Szczecin, badacz niezależny

tel.: +48692679473

e-mail: jmbnew@wp.pl

ORCID ID: https://orcid.org/0000-0001-5439-2319

\title{
Enantiosemia leksemów дружить i дружба
}

Słowa kluczowe: enantiosemia inherentna i adherentna, дружить, дружба

Enantiosemia, po raz pierwszy opisana przez Vikentija Szercla [Шерцль 1882-1884], definiowana jest jako rodzaj antonimii wewnętrznej, polegającej na współwystępowaniu w jednym wyrazie, morfemie lub w większej jednostce języka (frazemy ${ }^{1}$ ) dwóch przeciwstawnych treści. W środowisku językoznawczym określana jest także jako homoantonimia, homonimiczna antonimia, polisemia „patologiczna”, szczególny przypadek homonimii, wewnętrzna kombinacja homonimii i antonimii (patrz: [Wojan 2010, 214]), polaryzacja znaczeń (por. [Lachur 2004, 191])². Co ważne, ambiwalentne znaczenia (w szczególności konwersywów, np. снять [комнату]) ujawniają

\footnotetext{
1 Np. вертиться в голове pot. ekspr. 'несмотря на все усилия, никак не вспоминается что-л., хорошо известное, знакомое, но забытое в данный момент' і 'постоянно присутствует в сознании' [Федоров 2008, 65]. Więcej nt. enantiosemii w rosyjskiej frazeologii [Вознесенская 2011, 759-767]. Por. także spolaryzowane znaczenia wykrzyknień: Боже мой!

2 Niektórzy językoznawcy nazywając taki typ polisemicznych leksemów posiłkują się angielskim terminem kontronim (np. [Lewiński 2010, 69]. Termin ten w latach 60. ubiegłego wieku obok synonimicznego autoantonim (auto-antonym) pojawił się w pracach angielskich badaczy - Josepha Twadella Shipley'a (1960) i Jack'a Herringa (1962) [online] (https://en.wikipedia.org/wiki/Auto-antonym [13.02020]). W literaturze przedmiotu funkcjonuja ponadto alternatywne terminy o anglojęzycznej proweniencji, por. antagonim (antagonym), Janusowe stówka (Janus words) i in. [online] (http://www.fun-with-words. com/nym_autoantonyms.html [14.02.2020]).
} 
się jedynie w określonych kontekstach. Takie specyficzne zróżnicowanie semantemów wyrazów wieloznacznych ma charakter uniwersalny i jest rozpowszechnione w wielu językach naturalnych, np. pożyczać 'udzielać pożyczki' i 'zaciągać pożyczkę', franc. louer 'wynająć komuś' i 'wynająć od kogoś', łac. altus 'wysoki' i 'głęboki', jap. kage 'światło' i 'cień', arab. maqtarinum 'pan' i 'sługa', ang. twilight 'brzask' i 'zmierzch', ros. одолжumь 'pożyczyć komuś' i 'pożyczyć od kogoś' (za: [Lachur 2004, 191]), fiń. lainata 'pożyczyć komuś' i 'pożyczyć od kogoś' (za: [Wojan 2010, 215]), hiszp. alquilar 'wynająć komuś' i 'wynająć od kogoś', niem. ausleihen 'pożyczyć komuś' i 'pożyczyć od kogoś' i in.

W języku rosyjskim ze zjawiskiem antonimii wewnętrznej jednostek ciągłych spotkamy się wśród różnych części mowy, por.: бесценный 'не имеющий никакой цены' і 'имеющий очень высокую цену'3; буквально 'точно' i przen. 'фигурально выражаясь'; завязать 'начать' і 'закончить'; запаx 'аромат' і 'неприятный запах'.

Zdaniem Machmutovej rosyjskie słowniki rejestrują jedynie 250 enantiosemicznych jednostek, chociaż według lingwistki takich leksemów (i frazeologizmów) w badanym przez nią języku jest znacznie więcej [Махмутова 2009, 5]. Tezę tę podtrzymują i inni badacze, por.

Исследователи современного русского языка разграничивают ингерентную энантиосемию, которая реализуется в совмещении значений в слове и находит отражение в словарях, и адгерентную энантиосемию, которая не отражается в словарях, демонстрирует изменение коннотации и, как правило, сопровождается иронией [Маркасова 2008: 352].

Potwierdzają to również moje obserwacje dotyczące dwóch leksemów - czasownika дружить i rzeczownika дружба. Pomiędzy znaczeniami obu wyrazów także istnieją relacje antonimii wewnętrznej. Taka konstatacja faktów wynika zarówno z analizy źródeł leksykograficznych, jak i tekstów publicystycznych, literatury popularnej oraz przykładów zarejestrowanych przez

3 Zdaniem Lucii Machmutovej enantiosemiczność semantemów przymiotnika jest efektem procesów słowotwórczych i wynika z polaryzacji znaczeń konfiksu без- -ный: 'не имеющий чего-либо, на что указывает производящая основа' і 'имеющий что-либо, но в незначительной степени' [Махмутова 2009, 18]. W rezultacie derywacji powstają także enantiosemy prefiksalne i sufiksalne. Prefiksalny typ antonimii wewnętrznej reprezentuje m.in. czasownik прослушать 'совершение действия, названного мотивирующим глаголом' і 'упущение в реализации действия' [Махмутова 2009, 16]. Według badaczki także sufiksy rzeczownikowe, m.in. -онек/-енек, -охоньк/-ошоньк, -к- mają potencjał aby wyrażać jednocześnie znaczenia pejoratywne i melioratywne w zależności od tego w jakich kontekstach derywaty te zostały użyte [Махмутова 2009, 17]. 
Наииональный корпус русского языка (НКРЯ), сzy pochodzących z bezpośredniej lektury tekstów internetowych. Słowniki opisowe języka rosyjskiego odnotowują jedynie dwa znaczenia czasownika дружuть, por.:

1. (с кем) 'находиться с кем-л. в дружбе' (nр. дружить с детства),

2. (с чем) 'любить что-л., питать к чему-л. склонность, пристрастие' (np. Сын не дружит с математикой) [БТС 2003, 286].

Natomiast materiały leksykograficzne Новое в русской лексике. Словарные материаль 1989 (НРЛ-89) oraz Новье слова и значения. Словарь-справочник по материалам прессьи и литературь 90-х годов $X X$ века (HC3-90) rejestruja kolejny, antonimiczny względem pierwszego znaczenia (por. [БТС]), semantem 'объединяться на почве общей вражды к кому-, чему-л.' z kwalifikatorem żartobliwie, ironicznie [НРЛ-89 2001, 95; HC3-90 2009, 544]. W takim znaczeniu czasownikowi obowiązkowo towarzyszy przyimek nротив. Jak wynika z przywołanych $\mathrm{w}$ opracowaniach przykładów ilustracyjnych najwcześniejsze użycia leksemu w takim znaczeniu datowane są na koniec lat 80. ubiegłego wieku i pochodzą z utworu V. Krupina Будем как дети (1989) oraz czasopisma „Наш современник" (1989), zaś kolejne odnoszą się do lat 90. W następnych dziesięcioleciach (por. [НКРЯ]) semantem дружить [с кем?] против (кого?) niejednokrotnie pojawia się $\mathrm{w}$ tytułach prasowych, nawiązujących do bieżącej (najczęściej światowej) polityki. Por. najnowsze, wyekscerpowane przeze mnie z rosyjskojęzycznej prasy: „Президент Беларуси Александр Лукашенко заявил, что не хотел бы дружить с Украиной против кого-то, в частности, РФ или Китая" (Интерфакс-Украина z 04 października 2019$)^{4}$, „«Россия не дружит с другими странами против кого-то», заявил Путин” (РИА Новости z 13 października 2019)5, „Латвия зовет Батьку Лукашенко дружить против Кремля” („Свободна пресса” z 26 stycznia 2020) ${ }^{6}$, „Си Цзиньпин едет в Россию дружить против США” ( „Газета Экономика” z 29 таја 2019)7, „Трамп договорился с премьером Японии дружить против КНДР" (agencja informacyjna Красная Весна z 22 grudnia 2019)ㄱ, „Дружить против Ирана? WSJ раскрыл планы США по «спасению» американской экономики" (kanał

\footnotetext{
4 [online] https://interfax.com.ua/news/political/617044.html [11.02.2020].

5 [online] https://ria.ru/20191013/1559722772.html [11.02.2020].

6 [online] https://svpressa.ru/politic/article/255432/ [11.02.2020].

7 [online] http://raspp.ru/press_about/si-tszinpin-edet-v-rossiyu-druzhit-protiv-ssha2/ [11.02.2020].

8 https://rossaprimavera.ru/news/a9563605 [11.02.2020].
} 
Царьград z 19 września 2019)9 itd. Jak wynika z kolejnych kontekstów, w których pojawia się czasownik, można „przyjaźnić się” nie tylko przeciwko komuś, ale i w obronie czegoś, jakiś wspólnych interesów (дружить [с кем?] против [чего?]), por. tytuły prasowe: „Криптовалюта БРИКС поможет странам дружить против доллара" (portal Beincrypto.ru z 15 listopada 201) ${ }^{10}$, „Странная борьба с Европой: Эстония и Украина опоздали дружить против «Северного потока - 2»" (portal Цартград z 05 listopada 2019) ${ }^{11}$, „Лед и пламя: НОД призывает членов штаба Навального в Хабаровске дружить против коррупции" (portal Amurmedia.ru z 20 kwietnia 2017) ${ }^{12}$ i in.

Ponadto konstrukcja дружить против służy do opisywania relacji interpersonalnych, por.: „ИМХО, все же лучше дружить против администрации. Во всяком случае, в этом вопросе" ${ }^{13}$,

Радует лишь, что общие трудности, а иначе творящееся назвать трудно, чудесным образом сплотили горожан - они вместе выталкивали застрявшие авто, в складчину оплачивали услуги таксистов, рискнувших выехать в опасную погоду. Вот и дружить против коммунальщиков тоже решили сообща ${ }^{14}$.

Вдоволь наевшись, бурундучки натолкали ягод за обе щечки и понесли их родителям, конечно, каждый - своим. Родителям понравилось сладкое лакомство, и они не стали наказывать своих чад. Такие набеги на клубнику друзья совершали каждый день. Им нравилось дружить против хозяев ${ }^{15}$.

9 [online] https://tsargrad.tv/news/druzhit-protiv-irana-wsj-raskryl-plany-ssha-po-spa seniju-amerikanskoj-jekonomiki_217712 [11.02.2020].

10 O próbie dedolaryzacji przez członków bloku BRICS (Brazylii, Rosji, Indii, Chin i Republiki Południowej Afryki). Więcej: [online] https://beincrypto.ru/kriptovalyuta-brikspomozhet-stranam-druzhit-protiv-dollara/ [12.02.2020].

11 [online] https://tsargrad.tv/news/strannaja-borba-s-evropoj-jestonija-i-ukraina-opoz dali-druzhit-protiv-severnogo-potoka-2_224628 [12.02.2020].

12 [online] https://amurmedia.ru/news/584256/ [12.02.2020].

13 za НКРЯ: forum Красота, здоровье, отдых: Медицина и здоровье z dnia 11.12.2005 (dostęp 11.01.2020).

14 Za НКРЯ: „Новгородские ведомости” z 01.12.2012 [11.02.2020].

15 Н. Фоменко, Л. Плешивцева, А. Цыганов, С. Рулев, 2018, Давай дружить. Сборник стихов и рассказов для детей, [online] https://books.google.pl/books?id=zhNnD wAAQBAJ\&pg=PT118\&lpg=PT118\&dq=\%D0\%B4\%D1\%80\%D1\%83\%D0\%B6\%D0\%B $8 \% \mathrm{D} 1 \% 82 \% \mathrm{D} 1 \% 8 \mathrm{C}+\% \mathrm{D} 0 \% \mathrm{BF} \% \mathrm{D} 1 \% 80 \% \mathrm{D} 0 \% \mathrm{BE} \% \mathrm{D} 1 \% 82 \% \mathrm{D} 0 \% \mathrm{~B} 8 \% \mathrm{D} 0 \% \mathrm{~B} 2 \&$ source= bl\&ots $=$ my5HecPYOH\&sig $=$ ACfU3U3b6OpOHJaweDDDyiewu8JxdFDGA\&hl=pl\&sa $=$ $\mathrm{X} \& v e d=2$ ahUKEwiGn8CB7svnAhWPpYsKHUtrBzc4HhDoATACegQIBhAB \#v $=$ one page\&q=\%D0\%B4\%D1\%80\%D1\%83\%D0\%B6\%D0\%B8\%D1\%82\%D1\%8C\%20\%D0\%BF \%D1\%80\%D0\%BE\%D1\%82\%D0\%B8\%D0\%B2\&f=false [12.02.2020]. 
Не редкость для женской дружбы проявление ревности, соперничества, зависти и прочих не совсем дружеских качеств. Только женщины способны дружить не только с кем-то, но и против кого-то. Поэтому, в отличие от мужской дружбы, женская может быть представлена в совершенно разных форматах ${ }^{16}$.

Z kolei rzeczownik дружба w opracowaniach leksykograficznych definiowany jest w następujaccy sposób:

дружба: 1. 'отношения, основанные на взаимной привязанности, доверии, духовной близости, общности интересов и т.п.' (np. братская, мужская, солдатская, фронтовая дружба), 2. 'отношения между народами, странами, государствами, основанные на доверии, взаимопонимании и невмешательстве во внутренние дела друг друга' (np. Договор о дружбе и взаимопомощи) [БТС 2003, 285].

Tymczasem, jak świadczą o tym przytoczone poniżej przykłady, w języku rosyjskim w powszechnym użyciu jest także inne antonimiczne znaczenie leksemu. Por.:

Володин является противником выдвижения в думу по спискам «Единой России» Александра Мирошина, которому, возможно, придётся стать на предстоящих выборах конкурентом Вячеслава Викторовича. Эти обстоятельсва могли подтолкнуть вице-губернатора и областного прокурора к «дружбе против депутата». Об этом косвенно свидетельсвуют два факта. Во-первых, по сообщению газеты «Саратов-СП», Дмитрий Аяцков заявил, что в обязанности уполномоченного по защите прав человека не входит оценка деятельности правоохранительных органов и полномочия Александра Ландо могут быть прекращены досрочно ${ }^{17}$.

- Вот вся реакция Белого дома, правда, на всякий случай откомандировавшего в Думу Алексея Кудрина, но больше по бюджетным делам, а также «запланированного ранее» Михаила Касьянова. И даже неожиданный альянс «Яблока» с коммунистами в дружбе против Правительства из

\footnotetext{
16 Portal Passion.ru, [online] https://www.msn.com/ru-ru/lifestyle/family/\%D0\%BF \%D1\%80\%D0\%BE\%D1\%82\%D0\%B8\%D0\%B2-\%D0\%BA\%D0\%BE\%D0\%B3\%D0\%BE\%D0\%B4\%D1\%80\%D1\%83\%D0\%B6\%D0\%B8\%D0\%BC-3-\%D1\%82\%D0\%B8\%D0\%BF \%D0\%B0-\%D0\%BF\%D1\%80\%D0\%B8\%D1\%8F\%D1\%82\%D0\%B5\%D0\%BB\%D1\%8C\% D0\%BD\%D0\%B8\%D1\%86-\%D1\%81-\%D0\%BA\%D0\%BE\%D1\%82\%D0\%BE\%D1\%80\%D 1\%8B\%D0\%BC\%D0\%B8-\%D1\%81\%D1\%82\%D0\%BE\%D0\%B8\%D1\%82-\%D0\%B1\%D1 $\% 8 \mathrm{~B} \% \mathrm{D} 1 \% 82 \% \mathrm{D} 1 \% 8 \mathrm{C}-\% \mathrm{D} 0 \% \mathrm{BF} \% \mathrm{D} 0 \% \mathrm{BE} \% \mathrm{D} 0 \% \mathrm{~B} 2 \% \mathrm{D} 0 \% \mathrm{BD} \% \mathrm{D} 0 \% \mathrm{~B} 8 \% \mathrm{D} 0 \% \mathrm{BC} \% \mathrm{D} 0$ \%B0\%D1\%82\%D0\%B5\%D0\%BB\%D1\%8C\%D0\%BD\%D0\%B5\%D0\%B5/ar-BBWnxLO [12.02.2020].

17 Za НКРЯ: С. Любимов, Моральный вред с правом передачи, „Богатей” (Саратов), 17.04.2003 [11.02.2020].
} 
подобия хоть какой-то интриги превратился в бесконечную разборку союзников: кто, в чем и с кем согласен, а где позиции расходятся настолько, что впору забыть и об общем вотуме? Но тогда придется забыть и об информационных поводах со стопроцентной гарантией отображения в СМИ. $\mathrm{A}$ «Яблоку», так и не докатившемуся до СПС и не придумавшему собственного (хоть и малоэффективного) конька типа военной реформы, они нужны даже больше, чем коммунистам, в данном случае играющим на руку именно Явлинскому и поделившимся с ним своим «фирменным блюдом»18.

Już te dwa teksty prasowe pokazują, iż wyraźnie rzeczownik дружба nie oznacza w nich jakiejkolwiek przyjaźni, a wręcz odwrotnie, w tych kontekstach wyraża 'rodzaj aliansu, pseudoprzyjaźni (tutaj: wicegubernatora i prokuratora okręgowego oraz partii „Яблоко” i komunistów), nakierowanych przeciwko komuś trzeciemu - wrogowi, przeciwnikowi (tutaj odpowiednio: posłowi oraz rządowi), w imię realizacji wspólnych interesów'. Jego semantykę dodatkowo podkreśla przyimek против, tutaj w znaczeniu 'do walki z kimś, czymś', które uwidacznia się także w połączeniach z niektórymi innymi czasownikami, por. активно бороться против фашизма, хитрость, которую вы можете обратить против его хитрости, вооружить против римлян этрусского царя itp. Zdawałoby się, iż pojawienie się

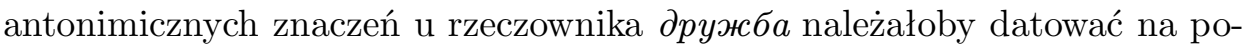
czątek obecnego stulecia (oba teksty pochodzą z 2003 r.). Jednak uważna lektura kontekstów nie pozwala na takie wnioski, gdyż w HKPЯ odnajdujemy następujący cytat pochodzący z monografii z 1948 roku:

Через посланных в горы Кофту и другие места эмиссаров Али-паша предложил французскому командированию союз и дружбу против русских. От Превезны Али-паша направился к городу Парга. Паргиоты решили города не сдавать и защищаться до последней капли крови ${ }^{19}$.

Także i tutaj mamy do czynienia z tym samym enantiosemicznym znaczeniem co wyżej. Tym razem owa „przyjaźń”, to swoisty alians jaki zaproponował Ali-Pasza Francuzom w celu połączenia sił do wali ze wspólnym wrogiem - Rosjanami.

W uzusie zaczyna funkcjonować wyrażenie дружить [с кем] / дружба [кого] против третьего, w którym komponent mpeтьего może być

18 Za НKРЯ: Т. Шкель, Яблочный nай, „Российская газета”, 2003 [11.02.2020].

19 Zа НКРЯ: Е.В. Тарле, 1948, Адмирал Уиаков на Средиземном море (1798-1800), Москва [11.02.2020]. 
wymieniony na inny, w zależności od bieżących potrzeb komunikacyjnych, np.: Дружили двое против третьего (tytuł utworu Olgi Szelpiakovej, 2014) ${ }^{20}$, nagłówki prasowe „Готовы дружить против третьего: социалисты и ACUM в Молдове могут создать коалицию" (agencja informacyjna News Front z 27.02.2019) ${ }^{21}$, „С Бойко согласен и Афанасьев - ситуация немало напоминает дружбу двоих против третьего" (portal Pravdapfo.ru, z dnia 13.11.2014)22, „Выборы в США или «дружба против третьего»” (portal Perevodika.ru z 25.04.2016) ${ }^{23}$, „Сотрудничество с кем-то не означает автоматически, что это дружба против третьего" (portal Panorama.am) ${ }^{24}$,

- Милая, Милая Аликс... Хотел бы я так! Но политика устроена иначе. Сегодня одни дружат с другими против третьих, потом другие с третьими начинают дружить против первых, а те с четвертыми - против них. Все время кто-то дружит против кого-то, чтобы что-нибудь чужое к рукам прибрать...25,

(Ведь самая крепкая дружба - это дружба против третьего и никогда не знаешь, как завтра будут развиваться события). Об этом прекрасно поведал известный историк Е.В. Тарле в своей книге «Талейран» 26.

20 [online] https://www.proza.ru/2014/08/21/1844 [18.02.2020].

21 [online] https://news-front.info/2019/02/27/gotovy-druzhit-protiv-tretego-sotsialistyi-acum-v-moldove-mogut-sozdat-koalitsiyu/ [19.02.2020].

22 [online] https://www.pravdapfo.ru/articles/mts-i-bilayn-v-chuvashii-druzhat-protivmegafona [19.02.2020].

23 [online] http://perevodika.ru/articles/1014433.html [19.02.2020].

24 [online] https://www.panorama.am/ru/news/2012/09/24/koziy-expert/676069

[19.02.2020].

25 Д. В. Миропольский, 2018, 1916. Война и Мир, Москва, Издательство АСТ, [online] https://books.google.pl/books?id=YBZfDwAAQBAJ\&pg=PT41\&lpg=PT41\&dq= \%D0\%B4\%D1\%80\%D1\%83\%D0\%B6\%D0\%B8\%D1\%82\%D1\%8C+\%D0\%BF\%D1\%80\%

D0\%BE\%D0\%B8\%D1\%82\%D0\%B2\&source=bl\&ots=ch9h5dGAKy\&sig=ACfU3U1nfQa GFiJkpPR8Df8t4hEboTu7gw\&hl=pl\&sa=X\&ved=2ahUKEwi_uqOvzsnnAhWdAhAIHT qXAeA4FBDoATAEegQIChAB\#v=onepage\&q=\%D0\%B4\%D1\%80\%D1\%83\%D0\%B6\% D0\%B8\%D1\%82\%D1\%8C\%20\%D0\%BF\%D1\%80\%D0\%BE\%D0\%B8\%D1\%82\%D0\%B2\& $\mathrm{f}=$ false [11.02.2020]. Porównaj także zasłyszane w rozmowie: Будем дружить против третьего (2007).

26 Проблемь европейской интеграции: правовой и культурологический аспектьл. Сборник научных статей, 2007, А.А. Дорская, С.А. Гончаров (ред.), Санкт-Петербург; [online] https://books.google.pl/books?id=eSR2CwAAQBAJ\&pg=PT465\&lpg=PT $465 \& \mathrm{dq}=\% \mathrm{D} 0 \% \mathrm{~B} 4 \% \mathrm{D} 1 \% 80 \% \mathrm{D} 1 \% 83 \% \mathrm{D} 0 \% \mathrm{~B} 6 \% \mathrm{D} 0 \% \mathrm{~B} 1 \% \mathrm{D} 0 \% \mathrm{~B} 0+\% \mathrm{D} 0 \% \mathrm{BF} \% \mathrm{D} 1 \% 80 \%$ D0\%BE\%D1\%82\%D0\%B8\%D0\%B2\&source=bl\&ots=A3we289ZRH\&sig=ACfU3U2VW JH5qChIU65W2f_301tmFLikOw\&hl=pl\&sa=X\&ved=2ahUKEwjE66Tt4uLnAhUjwqYK HTOPDb04ChDoATAJegQICBAB \#v=onepage \&q=\%D0\%B4\%D1\%80\%D1\%83\%D0\% B6\%D0\%B1\%D0\%B0\%20\%D0\%BF\%D1\%80\%D0\%BE\%D1\%82\%D0\%B8\%D0\%B2\&f= false [21.02.2020]. 
Spolaryzowane znaczenia leksemów дружить i дружба zasadzają się na przeciwstawieniu dwóch semów 'bezinteresowność' - 'interesowność' (obecny także w wyrażeniu дружить против третьего) i są poniekąd werbalizacją arystotelesowskiej koncepcji przyjaźni. Warto podkreślić, iż antonimiczne semantemy są zróżnicowane stylistycznie (neutralne - potoczne, niejednokrotnie z zabarwieniem ironicznym, żartobliwym ${ }^{27}$ ), a ponadto charakteryzują się odmienną łączliwością (дружuть с кем - дружить [с кем] против кого; дружба с кем - дружба [кого с кем] против кого, чего). Nieobecność enantiosemicznych znaczeń badanych leksemów w słownikach normatywnych może świadczyć o tym, iż zjawisko homoantonimii powstaje w pierwszej kolejności, zazwyczaj spontanicznie, w procesach komunikacyjnych (por. [Махмутова 2009, online]).

\section{Literatura}

Lachur Cz., 2004, Zarys językoznawstwa ogólnego, Opole.

Lewiński P., 2010, Metaplazmy i inne, „Rozprawy Komisji Językowej. Wrocławskie Towarzystwo Naukowe", nr 37, s. 65-70.

Wojan K., 2010, Wstęp do badań wieloznaczności leksemów w ujęciu kontrastywnym, Gdańsk.

BTS - Bol'šoj tolkovyj slovar' russkogo âzyka, 2003, S.A. Kuznecov (red.), Sankt-Peterburg. [БТС - Большой толковый словарь русского языка, 2003, С.А. Кузнецов (ред.), Санкт-Петербург.]

Voznesenskaâ M.M., 2011, Ènantiosemiâ v russkoj frazeologii, [v:] Komp'ûternâ̂a lingvistika $i$ intellektual'nye tehnologii: po materialam ežegodnoj Meždunarodnoj konferencii «Dialog» (Bekasovo, 25-29 mâ̂ 2011 g.), Vyp. 10 (17), Moskva, s. 759-767. [Вознесенская М.M., 2011, Энантиосемия в русской фразеологии, [w:] Компьютерная лингвистика и интеллектуальнье технологии: по материалам ежегодной Международной конферениии «Диалог» (Бекасово, 25-29 мая 2011 г.), Вып. 10 (17), Москва, c. $759-767$.

27 Stąd też zapis antonimicznych znaczeń w niektórych tekstach publicystycznych w cudzysłowie, por. „Европе и России выгодно «дружить против» Украины” (portal Tsn.ua z 06 maja 2012, от 06 мая 2012, [online] https://tsn.ua/ru/politika/evrope-irossii-vygodno-druzhit-protiv-ukrainy-politolog.html [12.02.2020]; tytuł prasowy „Ha встрече Зеленского и Лукашенко шутили о «дружбе против России»" (portal Svoboda.org z dnia 04 października 2019), [online] https://www.svoboda.org/a/30199251.html [21.02.2020]. 
Markasova E.V., 2008, Ritoričeskaâ ènantiosemiâ v korpuse russkogo âzyka povsednevnogo obŝeniâa «odin rečevoj den'», [v:] Komp'ûternâ̂ lingvistika i intellektual'nye tehnologii: po materialam ežegodnoj meždunarodnoj konferencii «Dialog» (2008). Periodičeskoe izdanie, vypusk 7 (14), A.E. Kibrik (glavred.), Moskva, s. 352-355. [Маркасова Е.В., 2008, Риторическая энантиосемия в корпусе русского языка повседневного общения «один речевой день», [w:] Компьютерная лингвистика и интеллектуальные технологии: по материалам ежегодной международной конференции «Диалог» (2008). Периодическое издание, выпуск 7 (14), А.Е. Кибрик (главред.), Москва, с. 352-355.]

Mahmutova L.R., 2009, Osnovnye tipy ènaniosemii v russkom âzyke, Kazan', avtoreferat dis...kand. filol. nauk [Махмутова Л.Р., 2009, Основные типь энаниосемии в русском языке, Казань, автореферат дис...канд. филол. наук], [online] https://www.dissercat.com/content/osnovnye-tipy-enantiose mii-v-sovremennom-russkom-yazyke [12.12.2019].

NRL-89 - Novoe v russkoj leksike. Slovarnye materialy 1989, 2001, N.V. Solov'ev (red.), Sankt-Peterburg. [НРЛ-89 - Новое в русской лексике. Словарные материальь 1989, 2001, Н.В. Соловьев (ред.), Санкт-Петербург.]

NSZ-90 - Novye slova i značeniâ. Slovar'-spravočnik po materialam pressy i literatury 90-h godov XX veka, 2009, T.N. Buceva (red.), t. 1, Sankt-Peterburg. [НС3-90 - Новье слова и значения. Словарь-справочник по материалам прессы и литературь 90-х годов ХХ века, 2009, Т.Н. Буцева (ред.), т. 1, Санкт-Петербург.]

Problemy evropejskojintegracii: pravovoj i kul'turologičeskij aspekty. Sbornik naučnyh statej, 2007, A.A. Dorskaâ, S.A. Gončarov (red.), Sankt-Peterburg. [Проблемы европейской интеграчии: правовой и культурологический аспектыл. Сборник научных статей, 2007, А.А. Дорская, С.А. Гончаров (ред.), Санкт-Петербург], [online] https://books.google.pl/books?id=eSR2 CwAAQBAJ\&pg =PT465\&lpg=PT465\&dq=\%D0\%B4\%D1\%80\%D1\%83\%D D0\%B6\%D0\%B1\%D0\%B0+\%D0\%BF\%D1\%80\%D0\%BE\%D1\%82\%D0\%B8 $\%$ D0\%B2\&source=bl\&ots $=$ A3we289ZRH\&sig $=$ ACfU3U2VWJH5qChIU65 W2f_301tmFLikOw\&hl=pl\&sa =X\&ved=2ahUKEwjE66Tt4uLnAhUjwqYK HTOPDb04ChDoATAJegQICBAB\#v=onepage\&q=\%D0\%B4\%D1\%80\%D $1 \% 83 \%$ D0\%B6\%D0\%B1\%D0\%B0\%20\%D0\%BF\%D1\%80\%D0\%BE\%D1\%8 $2 \% \mathrm{D} 0 \% \mathrm{~B} 8 \% \mathrm{D} 0 \% \mathrm{~B} 2 \& \mathrm{f}=$ false $[21.02 .2020]$.

Fedorov A.I., 2008, Frazeologičeskij slovar' russkogo literaturnogo âzyka, Moskva. [Федоров А.И., 2008, Фразеологический словарь русского литературного язылка, Москва.]

Šercl' V.I., 1883-1884, O slovah s protivopoložnymi značeniâmi (ili o tak nazyvaemoj ènatiosemii), „Filologičeskie zapiski”, vyp. V-VI. [Шерцль В.И., 1883-1884, О словах с противоположными значениями (или о так называемой энатиосемии), „Филологические записки”, вып. V-VI.] 


\section{ENANTIOSEMY OF WORDS ДРУЖИИЬ AND ДРУЖКА}

\section{ABSTRACT}

Key words: enantiosemy inherent and adherent, дружить, дружба

The phenomenon of enantiosemy is characteristic of many natural languages. Some of the polarized meanings of polisemous lexemes are registered in lexicographical studies (enantiosemy inherent), the part present in the usus, is not recorded in dictionaries (adherent enantiosemy). In Russian, the latter group is represented by antonymic semantems of the words дружить and дружба. 